\title{
Discordant Amino Acid Profiles in Monochorionic Twins with Twin-Twin Transfusion Syndrome
}

\author{
REKHA BAJORIA, MAGGIE HANCOCK, STUART WARD, STEPHEN W. D'SOUZA, AND \\ SUREN R. SOORANNA \\ Academic Units of Obstetrics and Gynaecology [R.B., S.W.]; and Child Health, St Mary's Hospital for \\ Women and Children [S.W.D.], University of Manchester, Manchester M13 OJH, U.K.; and Institute of \\ Obstetrics and Gynaecology, Hammersmith Trust Hospitals, Departments of Clinical Chemistry [M.H.] \\ and Maternal and Fetal Medicine [S.R.S.], Imperial College School of Medicine, Chelsea and Westminster \\ Hospital, London, SW10 9NH, U.K.
}

\begin{abstract}
ABS
To test the hypothesis that discordant growth in monochori-
onic (MC) twins occurs at least in part due to disparity in
placental amino acid transporter function, we measured plasma
amino acid levels by HPLC in maternal and fetal blood samples
collected at birth from gestational age matched twins with $(n=$
12) and without $(n=12)$ twin-twin transfusion syndrome
(TTTS). In the donor twin, fetal plasma concentrations and
feto-maternal ratios of five essential amino acids-valine $(p<$
0.001), leucine $(p<0.001)$, iso-leucine $(p<0.05)$, histidine
( $p<0.001)$ and L-arginine $(p<0.001)-$ were lower than the
recipient and non-TTTS twin pairs. Fetal concentrations of the
nonessential amino acids taurine $(p<0.001)$, serine $(p<0.01)$,
glycine $(p<0.001)$ and tyrosine $(p<0.05)$ were also markedly
lower in the donor than the recipient and non-TTTS twin pairs.
In contrast, the fetal alanine level in the donor twin was higher
than the recipient $(664 \pm 64$ versus $396 \pm 23 \mu \mathrm{M} ; p<0.001)$
and the non-TTTS twin pairs $(p<0.01)$. No such differences
between amino acid profiles in non-TTTS MC twin pairs were
\end{abstract}
Perinatal death and postnatal handicap are more common in monochorionic (MC) than dichorionic (DC) twins (1). The high perinatal mortality in MC twins has been attributed to the presence of vascular anastomoses in the placenta, which may lead to twin-twin transfusion syndrome (TTTS) (2).

Twin-twin transfusion syndrome is a chronic condition that presents in the early mid trimester of pregnancy, with characteristic discordance in fetal growth and amniotic fluid volume (1). Severe polyhydramnios develops in the larger "recipient" twin's sac, while oligohydramnios ensues in the growth restricted "donor" twin's sac. As pregnancy progresses, both fetuses are at a substantial risk of perinatal mortality and

Received February 7, 2000; accepted June 28, 2000.

Correspondence: Rekha Bajoria, University of Manchester, Academic Unit of Obstetrics and Gynaecology, St Mary's Hospital for Women and Children, Whitworth Park, Manchester M13 OJH, U.K.

This work was supported by the Research and Graduate Support Unit, University of Manchester. found. Maternal plasma amino acid levels between TTTS and non-TTTS groups were comparable. This study provides the first evidence that certain amino acids in the donor twin of chronic TTTS differ significantly from those of the co-twin while others were comparable between twin pairs. These data, therefore, argue against inter-twin transfusion as the sole cause of growth restriction of the donor twin and suggests instead that impaired placental transport of amino acids may be a likely mechanism. (Pediatr Res 48: 821-828, 2000)
MC, monochorionic

\section{Abbreviations}
$\mathbf{F} / \mathbf{M}$, feto-maternal ratio
IUGR, intrauterine growth restriction
TTTS, twin, twin transfusion syndrome
AGA, appropriate for gestational age
DC, dichorionic

morbidity. The donor twin is at risk of the well described complications of severe intrauterine growth retardation, while the recipient twin may develop hydrops, cardiac dilatation, myocardial hypertrophy, tricuspid regurgitation, right ventricular outflow obstruction, and renal failure (3).

Despite recent advances in the diagnostic and therapeutic modalities in fetal medicine, the treatment of chronic TTTS remains far from satisfactory $(4,5)$. This is attributed to the poor understanding of the patho-physiology of this enigmatic condition. Recent vascular anastomotic studies suggest that chronic TTTS, results from an "unbalanced" arrangement of surface communicating vessels $(6,7)$. In the normal MC twin placenta, a number of superficial artery-to-artery (AA) and vein-to-vein (VV) anastomoses compensate for the movement of blood along unidirectional deep artery-to-vein (AV) channels and while each fetus has an equivalent blood pressure there is no net flux between twin pairs $(6,7)$. However, as chronic TTTS is associated with a paucity of superficial anas- 
tomoses, unidirectional AV transfusions remain unchecked. Although, the severity of the disease process (in terms of intrauterine death, and hydrops) correlates with the placental macro-angioarchitecture and, in particular, the number of arterial-arterial (AA) anastomoses, fetal growth discordance appears to be independent of vascular shunts (8). This taken together with a recent observation of the absence of iron overload and/or depletion in TTTS twin pairs (9), indicates that factors other than inter-twin transfusion of blood and nutrients may be responsible for growth restriction (IUGR) in the donor twin.

Similarities between the growth patterns of donor twins and singleton IUGR fetuses have been noted for at least $30 \mathrm{y}$ (2). A marked discordance in the size of respective portions of the TTTS placenta has been described with the smaller "donor" twin being supported by a much reduced placental mass with diminished microvasculature $(8,10)$. Furthermore, umbilical artery blood flow by color Doppler in the TTTS donor twin, like the singleton IUGR, typically shows absent end diastolic flow $(5,11)$, while fetal blood sampling studies demonstrate evidence of chronic hypoxia and acidosis (12). Unlike the singleton IUGR fetus, in twin gestation, maternal nutrition, socio-economic factors, and smoking, cannot explain the disparity in growth between twin pairs. However, similar to severe singleton IUGR pregnancies, altered placental function leading to discordant placental transport of nutrients may well cause growth restriction of one of the MC twin pairs.

To test the hypothesis that discordant placental exchange of essential nutrients may contribute to growth restriction of the donor twin, we measured maternal and umbilical venous concentrations of essential and nonessential amino acids in MC twins with TTTS. The data were compared with gestational age matched concordant MC twin pairs without TTTS.

\section{METHODS}

Patients. Twenty-four women with MC twin pregnancies with or without TTTS were studied. Monochorionicity was established prenatally in the presence of concordant genitalia, intra-fetal membrane thickness $<2.0 \mathrm{~mm}$ and single placental mass, and was confirmed at birth by histology. The diagnosis of TTTS in monochorionic twins was made if the discordance in both estimated and actual birth weight was $\leq 15 \%$ and there was polyhydramnios in the larger twin's sac [amniotic fluid index (AFI) of $\geq 40 \mathrm{~cm}$ ] and anhydramnios or oligohydramnios with the IUGR twin (AFI of $\leq 2 \mathrm{~cm}$ ) (5). All TTTS pregnancies were managed by amnioreduction. This study, only included those pregnancies were both fetuses were born alive. MC twins with concordant growth and normal amniotic fluid volumes in both sacs (AFI of $\leq 24 \mathrm{~cm}$ ) throughout pregnancy constituted the control group. All pregnancies were monitored by serial ultrasound scans for fetal growth, amniotic fluid volume and hydrops.

Collection of samples. Maternal blood samples were obtained from the antecubital vein and umbilical venous blood from a segment of cord clamped at both ends at the birth of each twin. Blood samples were collected into tubes containing ethylenediamine tetra-acetic acid. The samples were centri- fuged, and the plasma stored at $-70^{\circ} \mathrm{C}$ until batch assay was performed. Informed consent was obtained from all women as required by the hospital research ethics committee.

Measurement of amino acids. The concentrations of amino acids were determined by adding $0.02 \mathrm{~mL}$ of $35 \%$ (wt/vol) sulfosalicylic acid to $0.2 \mathrm{~mL}$ of plasma, mixed and left to stand for $5 \mathrm{~min}$. After centrifugation for $5 \mathrm{~min}$ at $1100 \mathrm{~g}, 0.1 \mathrm{~mL}$ was diluted with an equal volume of s-aminoethylleysteine $(0.2$ $\mathrm{mmol} / \mathrm{L}$ ) mixed and re-centrifuged. $\mathrm{O} .05 \mathrm{~mL}$ of supernatant was applied to the column (Beckman System 6300 high performance analyser, Beckman Instruments, U.K., Ltd) and eluted with a 3-buffer system (Beckman lithium buffers A, B, C). Peaks were detected after reaction with ninhydrin and integrated using the Beckman 406 analogue to digital converter and Beckman System Gold Software. A series of amino acid solutions from Beckman were used as reference amino acid standards. Additional standards were obtained from Sigma Chemical Co. Chemical Company Limited (Poole, U.K.) (glutamine, asparagine, tryptophan). Amino acid concentrations are presented as $\mu \mathrm{mol} / \mathrm{L}$.

Data analysis. Clinical data are expressed as medians and ranges, while amino acid concentrations are expressed as mean \pm SEM. For parametric data, the paired $t$ test was used to compare values within twin pairs and the Student's $t$ test between groups. Fisher's exact test was used for blocked comparisons. For nonparametric data, comparisons between groups were performed by the Mann-Whitney test. Percentage growth discordance was defined as the difference in birth weights expressed as a proportion of the weight of the larger twin. In the control group, the heavier twin was labeled as twin 1 and lighter as twin 2.

\section{RESULTS}

Clinical features of the MC twins with or without TTTS are given in Table 1. All patients in the TTTS group were treated by amnioreduction.

\section{Essential Amino Acids}

Maternal levels. Maternal levels of all essential amino acids were similar between TTTS and non-TTTS twin groups (Table 2).

Fetal levels and $\mathbf{F} / \mathbf{M}$ ratios. Total concentrations of nine essential amino acids in the donor twin of chronic midtrimester TTTS pregnancies were lower than those in the recipient twin $(1274 \pm 53 \mu \mathrm{M}$ versus $1758 \pm 70 \mu \mathrm{M} ; p<$ 0.001 ) and the control group (Fig. 1). No such differences were present between non-TTTS twin pairs $(1736 \pm 52 \mu \mathrm{M}$ versus $1763 \pm 51 \mu \mathrm{M} ; \mathrm{P}=\mathrm{NS}$ ) and the recipient twin. Concentrations of branched chain amino acids were markedly reduced in the donor than the recipient twin $(345 \pm 12 \mu \mathrm{M}$ versus $631 \pm 35$ $\mu \mathrm{M} ; p<0.001$ ) (Fig. 1) and the non-TTTS twin pairs. There were no differences in branched amino acids levels between non-TTTS twin pairs $(572 \pm 19 \mu \mathrm{M}$ versus $602 \pm 28 \mu \mathrm{M}$; $\mathrm{P}=\mathrm{NS}$ ) and the recipient twin of TTTS pregnancies. In the donor twin, plasma concentrations and F/M ratios of valine, isoleucine, leucine, L-arginine and histidine were significantly reduced compared with the recipient twin and the non-TTTS 
Table 1. Clinical features of pregnancies with mid-trimester TTTS in comparison to the control group

\begin{tabular}{|c|c|c|c|}
\hline Parameters & TTTS & Control & $p$ Value \\
\hline $\begin{array}{l}\text { Gestational age at } \\
\text { diagnosis (weeks) }\end{array}$ & $\begin{array}{c}21 \\
(16-28)\end{array}$ & & \\
\hline $\begin{array}{l}\text { Max amniotic fluid volume } \\
\text { (L) }\end{array}$ & $\begin{array}{c}54 \\
(38-79)\end{array}$ & $\begin{array}{c}14 \\
(12-22)\end{array}$ & $<0.01$ \\
\hline $\begin{array}{l}\text { Max discordance in } \\
\text { estimated birth weight } \\
(\mathrm{g})\end{array}$ & $\begin{array}{c}40 \\
(20-55)\end{array}$ & $\begin{array}{c}3 \\
(1-12)\end{array}$ & $<0.001$ \\
\hline \multicolumn{4}{|l|}{ Estimated birth weight $(\mathrm{g})$} \\
\hline Recipient/Twin 1 & $\begin{array}{c}487^{*} \\
(273-2190)\end{array}$ & $\begin{array}{c}1065 \\
(374-2063)\end{array}$ & \\
\hline Donor/Twin 2 & $\begin{array}{c}383 \\
(185-1198)\end{array}$ & $\begin{array}{c}1002 \\
(366-19250\end{array}$ & \\
\hline No. of Amnioreductions & $\begin{array}{c}2 \\
(1-7)\end{array}$ & & \\
\hline Total volume removed (L) & $\begin{array}{c}5.0 \\
(1-19)\end{array}$ & & \\
\hline $\begin{array}{l}\text { Hemoglobin discordance at } \\
\text { birth }(\mathrm{g} / \mathrm{dl})\end{array}$ & $\begin{array}{c}3 \\
(0.1-4)\end{array}$ & $\begin{array}{c}0.8 \\
(0.3-5.2)\end{array}$ & NS \\
\hline $\begin{array}{l}\text { Gestational age at delivery } \\
\text { (weeks) }\end{array}$ & $\begin{array}{c}30 \\
(26-36)\end{array}$ & $\begin{array}{c}32 \\
(26-38)\end{array}$ & NS \\
\hline $\begin{array}{l}\text { Birth weight discordance } \\
\text { (\%) }\end{array}$ & $\begin{array}{c}24 \\
(16-38)\end{array}$ & $\begin{array}{c}3.5 \\
(1-13)\end{array}$ & $<0.001$ \\
\hline \multicolumn{4}{|l|}{ Birth weight $(\mathrm{g})$} \\
\hline Recipient/Twin-1 & $\begin{array}{c}1585^{*} \\
(800-2245)\end{array}$ & $\begin{array}{c}1810 \\
(690-3154)\end{array}$ & NS \\
\hline Donor/Twin-2 & $\begin{array}{c}1155 \\
(580-1755)\end{array}$ & $\begin{array}{c}1750 \\
(660-3006)\end{array}$ & $<0.001$ \\
\hline$\Delta$ Arterial cord $\mathrm{pH}$ & $\begin{array}{c}0.12 \\
(0.06-0.18)\end{array}$ & $\begin{array}{c}0.04 \\
(-0.09-0.22)\end{array}$ & $<0.01$ \\
\hline $\begin{array}{l}\Delta \text { Arterial cord } \mathrm{pO}_{2} \\
(\mathrm{~mm} \mathrm{Hg})\end{array}$ & $\begin{array}{l}9.0 \\
(0.9-25)\end{array}$ & $\begin{array}{c}1.4 \\
(-2.6-13.6)\end{array}$ & $<0.01$ \\
\hline $\begin{array}{l}\Delta \text { Fetal haemoglobin } \\
(\mathrm{g} / \mathrm{dl})\end{array}$ & $\begin{array}{c}3.0 \\
(0.1-4)\end{array}$ & $\begin{array}{c}1.3 \\
(0.3-5.2)\end{array}$ & NS \\
\hline \multicolumn{4}{|l|}{ Mode of delivery } \\
\hline Caesarean section & $11 / 12$ & $8 / 12$ & NS \\
\hline Vaginal delivery & $1 / 12$ & $4 / 12$ & NS \\
\hline Perinatal mortality & $10 / 24$ & $2 / 24$ & $<0.001$ \\
\hline
\end{tabular}

Comparison between recipient and donor twin $p<0.001$. Values are median (range).

twin pairs (Fig. 2). However, the plasma concentrations of methionine, threonine, phenylalanine and lysine were comparable between TTTS and non-TTTS twin pairs. The essential amino acid profiles were comparable between twin pairs of the non-TTTS group and that of the recipient twin. (Table 3).

\section{Non-Essential Amino-Acids}

Maternal levels. The maternal concentrations of all nonessential amino acids were similar in the non-TTTS and TTTS groups (Table 2).

Fetal levels and F/M ratios. Total nonessential amino acids levels at birth were comparable between TTTS $(2104 \pm 74$ $\mu \mathrm{mol}$ versus $1957 \pm 93 \mu \mathrm{mol} ; p=\mathrm{NS})$ and non-TTTS twin pairs $(1935 \pm 85 \mu \mathrm{mol}$ versus $2007 \pm 100 \mu \mathrm{mol} ; \mathrm{P}=\mathrm{NS})$. However, the ratios of total nonessential to essential amino acids were significantly higher in the donor than the recipient twin of TTTS $(1.55 \pm 0.08$ versus $1.20 \pm 0.03 ; p<0.001)$ and control group. No such differences were found between nonTTTS twin pairs $(1.12 \pm 0.05$ versus $1.14 \pm 0.04 ; p=\mathrm{NS})$ (Fig. 1).
The concentrations and F/M ratios of taurine, serine, tyrosine, and glycine were lower in the donor than the recipient twin, and the non-TTTS twin pairs (Fig. 3). In contrast, in the donor twin, the plasma levels and $\mathrm{F} / \mathrm{M}$ ratios of alanine were higher than the recipient twin, and the control MC twin pairs. Feto-maternal ratios and plasma levels of taurine were higher in the recipient than the donor twin and non-TTTS twin pairs. Concentrations of glutamic acid, ornithine, hydroxyproline, and proline were similar between the recipient and donor twin (Tables 3 and 4). In contrast, fetal levels and $\mathrm{F} / \mathrm{M}$ ratios of all nonessential amino acids were comparable between control $\mathrm{MC}$ twin pairs.

\section{DISCUSSION}

This study demonstrates that the fetal concentrations and feto-maternal ratios of certain essential and nonessential amino acids in the donor twin of chronic mid-trimester TTTS differ markedly from those of the co-recipient twin and control MC twin pairs. Many studies have addressed amino acid concentrations in normal and abnormal singleton pregnancies both in utero and at birth (13-15). However, little or no information is available on the feto-maternal concentrations of amino acids in twin pregnancies. This information is pertinent to understand the cause and effect of supply and metabolism of amino acids on fetal growth in MC pregnancies.

In this prospective study, the more recent ultrasound criteria of gross polyhydramnios in the larger twin with severe oligohydramnios in the smaller twin in the absence of chromosomal and structural defects was used for the diagnosis of chronic TTTS (1). The older criteria of neonatal $\mathrm{Hb}$ differences of $5 \mathrm{~g} / \mathrm{dL}$ was not used for the diagnosis of TTTS as recent research suggests that such $\mathrm{Hb}$ differences can also occur in dichorionic and monochorionic twins without discordance in birth weights (16). Indeed hematological discordance is unlikely in mid-trimester cases of TTTS investigated by fetal blood sampling $(17,18)$.

We studied monochorionic twin pregnancies with and without TTTS as a clinical model in an attempt to improve our understanding of the factors, which regulate intra-uterine fetal growth. TTTS, which is a common complication of monochorionic pregnancies, is characteristically associated with discordant fetal growth. In addition, this model has numerous advantages in that, it enables us to dissect the effects of substrate availability, genetic potential, maternal and placental factors on fetal growth. In monochorionic twins, it is highly unlikely that severe growth restriction of one of the twin pairs is due to differences in their genetic or constitutional growth potential. Similarly, as twins share the same intrauterine environment, variation in fetal growth within twin pairs is unlikely to be due to differences in maternal diet or cumulative nutritional status, smoking, hypertension, preeclampsia, and diabetes. Therefore, the twin model is useful to establish the potential role of the fetal supply line, and in particular placentation, which is known to play an important part in determining variations in growth rates (19). It is frequently stated that, the altered growth pattern in the donor twin is an adaptation in response to uncompensated unidirectional transfer of blood and nutrients to the 
Table 2. Maternal concentrations of amino acids in TTTS and control MC twin pregnancies

\begin{tabular}{|c|c|c|c|}
\hline & $\begin{array}{l}\text { TTTS } \\
\text { group }\end{array}$ & $\begin{array}{c}\text { MC } \\
\text { concordant } \\
\text { control } \\
\text { group }\end{array}$ & $p$ value \\
\hline \multicolumn{4}{|l|}{ Essential } \\
\hline Valine & $168 \pm 9$ & $170 \pm 16$ & 0.89 \\
\hline Leucine & $72 \pm 6$ & $63 \pm 5$ & 0.23 \\
\hline Isoleucine & $114 \pm 11$ & $115 \pm 21$ & 0.95 \\
\hline Threonine & $159 \pm 10$ & $143 \pm 12$ & 0.26 \\
\hline Phenylalanine & $69 \pm 17$ & $82 \pm 19$ & 0.43 \\
\hline Methionine & $16 \pm 1$ & $21 \pm 3$ & 0.11 \\
\hline Lysine & $172 \pm 7$ & $158 \pm 11$ & 0.22 \\
\hline Histidine & $91 \pm 4$ & $88 \pm 10$ & 0.76 \\
\hline Arginine & $79 \pm 7$ & $65 \pm 9$ & 0.17 \\
\hline \multicolumn{4}{|l|}{ None-essential } \\
\hline Taurine & $95 \pm 14$ & $86 \pm 9$ & 0.70 \\
\hline Serine & $134 \pm 8$ & $128 \pm 10$ & 0.71 \\
\hline Glutamic acid & $389 \pm 28$ & $417 \pm 40$ & 0.56 \\
\hline Glycine & $162 \pm 10$ & $152 \pm 11$ & 0.62 \\
\hline Alanine & $224 \pm 15$ & $229 \pm 15$ & 0.27 \\
\hline Tyrosine & $51 \pm 3$ & $50 \pm 5$ & 0.74 \\
\hline Tryptophane & $41 \pm 2$ & $39 \pm 3$ & 0.44 \\
\hline Ornithine & $35 \pm 3$ & $43 \pm 5$ & 0.12 \\
\hline Hydroxyproline & $23 \pm 3$ & $31 \pm 4$ & 0.40 \\
\hline Proline & $127 \pm 8$ & $137 \pm 8$ & 0.37 \\
\hline
\end{tabular}

All values are expressed as mean \pm SEM.

recipient twin $(2,4)$. However, our data show that fetal plasma concentrations of 10 amino acids in the donor twin differ significantly from those the of recipient twin, while levels of other amino acids between twin pairs are comparable. This finding argues against the general view that IUGR in the donor twin occurs as a consequence of simple inter-twin transfer of blood between the twin pairs.

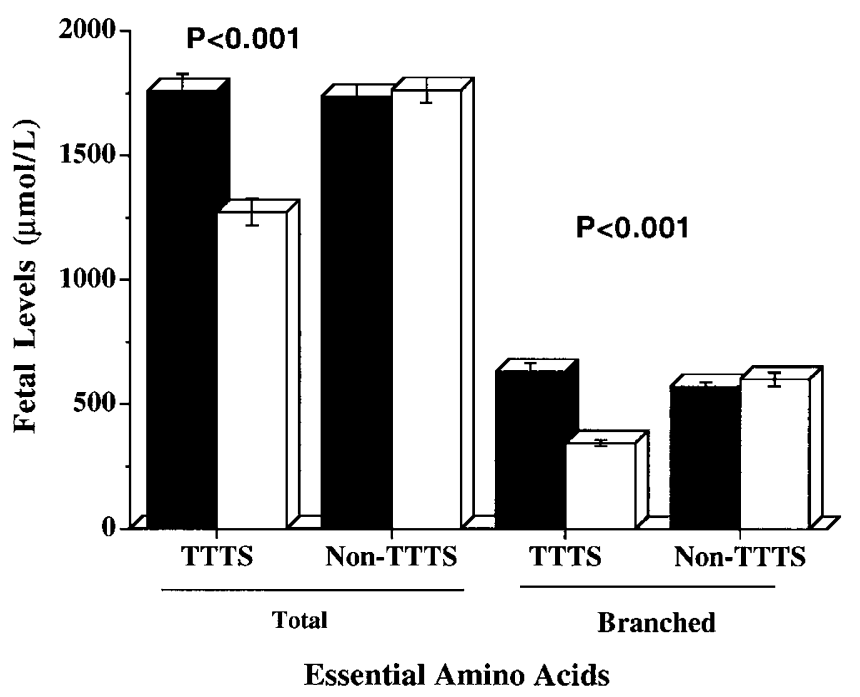

Figure 1. The fetal levels of total and branched chain essential amino acids between TTTS and non-TTTS twin pairs are compared. Closed and open bars represent, respectively, recipient and donor twin in the TTTS group, and twin 1 and twin 2 in the non-TTTS group.

Notwithstanding this, decreases in the plasma concentrations of total essential amino acids and increases in the ratios of nonessential to essential amino acids in the growth restricted donor twins, suggest that impaired placental function, may contribute to IUGR of one of the MC twin pairs. Similar differences between total fetal amino acids concentrations have been reported in singleton pregnancies, when IUGR and AGA fetuses were compared $(20,21)$. These differences in amino acid profiles between $\mathrm{MC}$ twin pairs with different growth potentials could be a result of reduced perfusion and, thereby, transport across the placenta. Little or no information is avail-
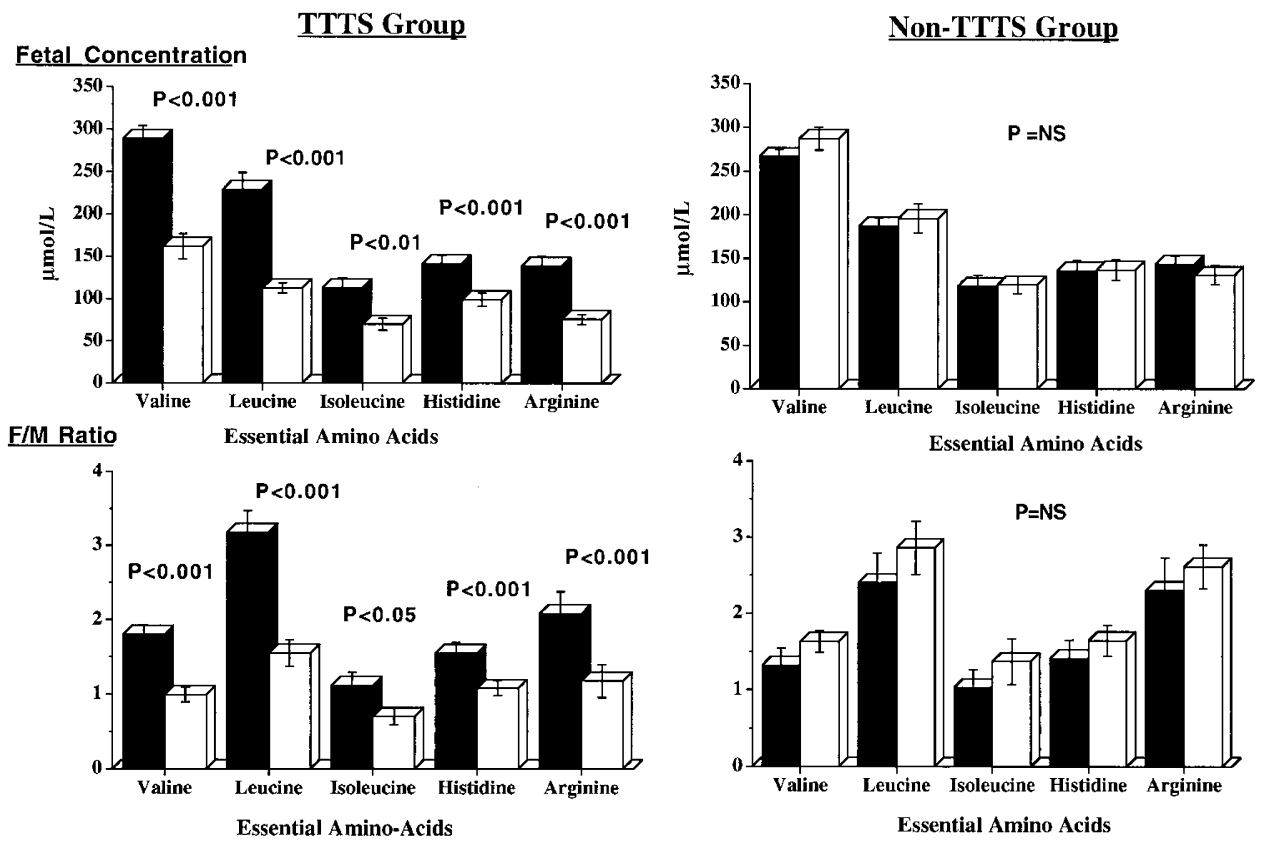

Figure 2. The fetal concentrations and feto-maternal ratios of essential amino acid levels between MC twin pairs with TTTS and without TTTS are compared. Closed and open bars represent, respectively, recipient and donor twin in the TTTS group, and twin 1 and twin 2 in the non-TTTS group. 
TTTS Group

\section{Fetal Concentration}

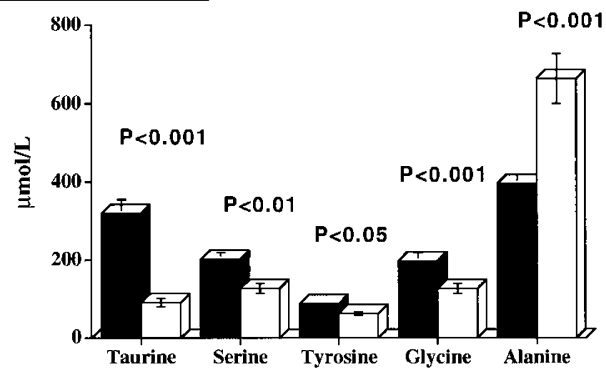

F/M Ratio

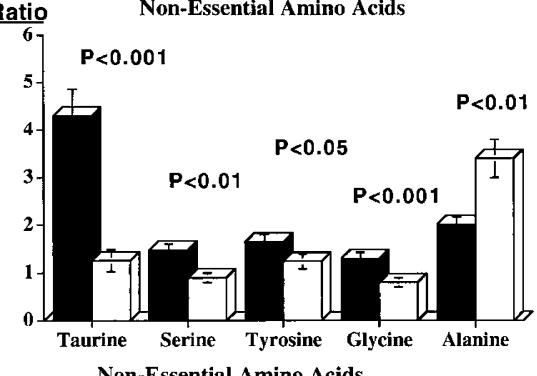

Non-TTTS Group
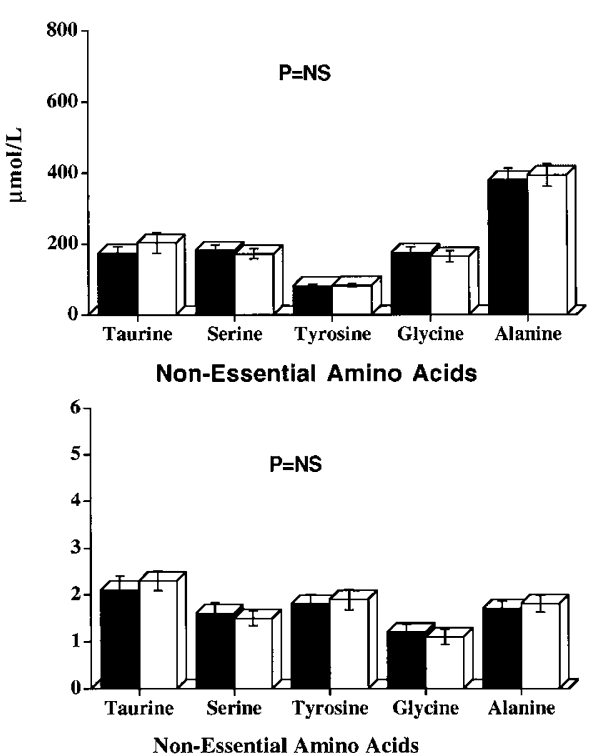

Figure 3. The fetal and feto-maternal concentrations of nonessential amino acid levels between MC twin pairs with TTTS and without TTTS are compared. Closed and open bars represent, respectively, recipient and donor twin in the TTTS group, and twin 1 and twin 2 in the non-TTTS group.

TABLE 3. Comparison of fetal concentrations of amino acids between TTTS and non-TTTS twin pairs

\begin{tabular}{|c|c|c|c|c|c|c|c|}
\hline & Donor (D) & $\begin{array}{l}\text { Recipient } \\
\text { (R) }\end{array}$ & $\begin{array}{l}\mathrm{D} \text { vs } \mathrm{R} p \\
\text { value }\end{array}$ & $\begin{array}{l}\text { Twin } 1 \\
\text { (T1) }\end{array}$ & $\begin{array}{c}\text { Twin } 2 \\
\text { (T2) }\end{array}$ & $\begin{array}{c}\mathrm{D} \text { vs } \mathrm{T} 1 \\
\text { and/or T2 } \\
p \text { value }\end{array}$ & $\begin{array}{c}\mathrm{R} \text { vs } \mathrm{T} 1 \\
\text { and/or } \mathrm{T} 2 \\
p \text { value }\end{array}$ \\
\hline \multicolumn{8}{|l|}{ Essential } \\
\hline Leucine & $113 \pm 6$ & $229 \pm 20$ & $<0.001$ & $187 \pm 10$ & $196 \pm 17$ & $<0.001$ & NS \\
\hline Isoleucine & $70 \pm 7$ & $113 \pm 12$ & $<0.01$ & $118 \pm 13$ & $120 \pm 10$ & $<0.01$ & NS \\
\hline Threonine & $268 \pm 18$ & $291 \pm 24$ & NS & $322 \pm 46$ & $335 \pm 46$ & NS & NS \\
\hline Lysine & $370 \pm 25$ & $411 \pm 25$ & NS & $401 \pm 26$ & $397 \pm 19$ & NS & NS \\
\hline Histidine & $99 \pm 8$ & $142 \pm 10$ & $<0.001$ & $136 \pm 12$ & $137 \pm 12$ & $<0.05$ & NS \\
\hline Arginine & $76 \pm 6$ & $139 \pm 12$ & $<0.001$ & $144 \pm 9$ & $131 \pm 11$ & $<0.001$ & NS \\
\hline \multicolumn{8}{|l|}{ Non-essential } \\
\hline Taurine & $91 \pm 11$ & $320 \pm 35$ & $<0.001$ & $174 \pm 18$ & $203 \pm 29$ & $<0.01$ & $<0.01$ \\
\hline Serine & $127 \pm 13$ & $202 \pm 18$ & $<0.01$ & $182 \pm 16$ & $172 \pm 14$ & $<0.05$ & NS \\
\hline Tryptophan & $48 \pm 4$ & $57 \pm 5$ & NS & $52 \pm 4$ & $56 \pm 3$ & NS & NS \\
\hline Ornithine & $115 \pm 16$ & $149 \pm 13$ & NS & $122 \pm 12$ & $126 \pm 11$ & NS & NS \\
\hline Hydroxyproline & $43 \pm 4$ & $36 \pm 2$ & NS & $32 \pm 3$ & $29 \pm 2$ & NS & NS \\
\hline Proline & $180 \pm 11$ & $203 \pm 12$ & NS & $209 \pm 11$ & $199 \pm 7$ & NS & NS \\
\hline
\end{tabular}

No significant differences were found between twin 1 and twin 2 for both essential and non-essential amino acids. All values are expressed as mean \pm SEM.

able describing utero-placental blood flow in discordant MC twin pregnancies. However, abnormal uterine artery velocimetry is present in the recipient twin with severe polyhydramnios (22). With the restoration of normal amniotic fluid volume by amnioreduction, improvement of the uterine artery impedance indices suggests that abnormal utero-placental perfusion in the recipient twin is due to increased intra-amniotic pressure rather than lack of trophoblastic invasion of the spiral arteries. Alternatively, discordant amino acid concentrations could simply be due to reduced extraction from the placenta. Indeed, clinical observations of absent end diastolic flow velocity in the umbilical artery of the donor twin are suggestive of increased resistance to feto-placental blood flow $(5,11)$. However, selective differences in amino acid profiles between TTTS twin pairs cannot simply be explained by impaired placental perfusion. The differences in amino acid profiles between donor and recipient twins might be attributed to fetal factors. Recent data suggests that insulin like growth factors may also influence uptake and net flux of amino acids across the placenta $(23,24)$. Therefore it is plausible that reduced amino acid concentrations 
Table 4. Comparison of feto-maternal ratios of amino acids between TTTS and non-TTTS twin pairs

\begin{tabular}{|c|c|c|c|c|c|c|c|}
\hline & Donor (D) & $\begin{array}{l}\text { Recipient } \\
\text { (R) }\end{array}$ & $\begin{array}{l}\mathrm{D} \text { vs } \mathrm{R} \\
p \text { value }\end{array}$ & $\begin{array}{c}\text { Twin } 1 \\
\text { (T1) }\end{array}$ & $\begin{array}{c}\text { Twin } 2 \\
\text { (T2) }\end{array}$ & $\begin{array}{c}\mathrm{D} \text { vs } \mathrm{T} 1 \\
\text { and/or } \mathrm{T} 2 \\
p \text { value }\end{array}$ & $\begin{array}{c}\mathrm{R} \text { vs } \mathrm{T} 1 \\
\text { and/or } \mathrm{T} 2 \\
p \text { value }\end{array}$ \\
\hline \multicolumn{8}{|l|}{ Essential } \\
\hline Leucine & $1.5 \pm 0.2$ & $3.2 \pm 0.3$ & $<0.001$ & $2.4 \pm 0.4$ & $2.9 \pm 0.3$ & $<0.001$ & NS \\
\hline Isoleucine & $0.7 \pm 0.1$ & $1.1 \pm 0.2$ & $<0.05$ & $1.0 \pm 0.2$ & $1.4 \pm 0.3$ & $<0.05$ & NS \\
\hline Threonine & $1.9 \pm 0.2$ & $2.0 \pm 0.2$ & NS & $2.4 \pm 0.5$ & $3.0 \pm 0.4$ & NS & NS \\
\hline Lysine & $2.3 \pm 0.1$ & $2.5 \pm 0.1$ & NS & $2.4 \pm 0.4$ & $2.8 \pm 0.2$ & NS & NS \\
\hline Histidine & $1.1 \pm 0.1$ & $1.5 \pm 0.1$ & $<0.001$ & $1.4 \pm 0.2$ & $1.6 \pm 0.2$ & $<0.01$ & NS \\
\hline Arginine & $1.2 \pm 0.2$ & $2.1 \pm 0.3$ & $<0.001$ & $2.3 \pm 0.4$ & $2.6 \pm 0.3$ & $<0.001$ & NS \\
\hline \multicolumn{8}{|l|}{ Non-essential } \\
\hline Taurine & $1.3 \pm 0.2$ & $4.3 \pm 0.6$ & $<0.001$ & $2.1 \pm 0.2$ & $2.3 \pm 0.2$ & $<0.01$ & $<0.01$ \\
\hline Serine & $0.9 \pm 0.1$ & $1.5 \pm 0.1$ & $<0.01$ & $1.6 \pm 0.2$ & $1.5 \pm 0.2$ & $<0.05$ & NS \\
\hline Tryptophan & $1.2 \pm 0.1$ & $1.4 \pm 0.1$ & NS & $1.5 \pm 0.2$ & $1.6 \pm 0.3$ & NS & NS \\
\hline Ornithine & $4.3 \pm 0.8$ & $4.9 \pm 0.7$ & NS & $3.3 \pm 0.6$ & $3.4 \pm 0.5$ & NS & NS \\
\hline Hydroxyproline & $1.8 \pm 0.2$ & $1.4 \pm 0.1$ & NS & $1.2 \pm 0.2$ & $1.2 \pm 0.2$ & NS & NS \\
\hline Proline & $1.5 \pm 0.2$ & $1.7 \pm 0.2$ & NS & $1.6 \pm 0.1$ & $1.5 \pm 0.1$ & NS & NS \\
\hline
\end{tabular}

No significant differences were found between twin 1 and twin 2 for both essential and non-essential amino acids. All values are expressed as mean \pm SEM.

in the donor twin compared with that of the recipient may simply be attributed to the differences in the fetal concentrations of IGF-I. Although no information is available on the IGF axis in MC twins with TTTS, singleton IUGR fetuses are known to have reduced IGF-I levels compared with AGA fetuses (25). Alternatively, impaired placental exchange, fetal utilization and/or metabolism of some of the amino acids may also attribute for selective differences in amino acid concentrations between TTTS twin pairs.

In singleton pregnancies, amino acids are transferred from mother to fetus by specific transporters in the placenta and the activity of such transporters are reduced in diabetic, SGA and severe IUGR babies (26-29). The reduction in fetal plasma amino acid concentrations in the donor twin is unlikely to be confined to a specific amino acid transport group, although branched chain and cationic amino acids are more severely affected.

Neutral branched chain concentrations of the essential amino acids valine, leucine, and iso-leucine, are reduced in the donor compared with the recipient twin. These amino acids are nutritionally essential for the growing fetus. Lower fetal levels in the donor twin could be due to reduced placental transport. Branched chain amino acids share the " $\mathrm{L}$ " transporter system in the human placenta (30). Recent in vitro data also suggests that the system $\mathrm{L}$ amino acid transporter has reduced activity in the microvillous membrane vesicles isolated from the human placenta of severe IUGR pregnancies (27). Alternatively, diminished plasma amino acid levels might be a reflection of increased amino acid utilization by the donor twins. Although, in this study this question was not addressed, in singleton pregnancies, umbilical veno-arterial gradient of total amino acid concentrations between AGA and IUGR fetuses have been shown to be comparable $(21,31)$.
The concentration of the cationic amino acid L-arginine was significantly reduced in the donor compared with the recipient twin. Previous studies in singleton pregnancies have shown that plasma L-arginine concentrations are not consistently different in IUGR and AGA fetuses $(13,14,28)$. Recent data suggests that the activity of L-arginine transporters $\mathrm{y}+$ and $\mathrm{y}+\mathrm{L}$ in the microvillous membrane are not impaired in singleton IUGR placentas (32). However, in the basal membrane, activity of the cationic transporter in the IUGR placenta is shown to be reduced (27). These findings suggest that a reduction in the activity of the $\mathrm{y}+\mathrm{L}$ amino acid transporter may alter net transport of L-arginine across the basal membrane to the fetus and thereby contribute to the low L-arginine concentration observed in the donor twin. We have further considered the possibility that the low L-arginine concentrations may reflect increased utilization by the placenta. This may occur since L-arginine is a substrate for nitric oxide production in an attempt to reduce increased feto-placental vascular resistance associated with donor twin in chronic TTTS pregnancies (11). Significantly higher nitrite concentrations in the umbilical venous plasma has also been reported in singleton pregnancies complicated by intrauterine growth restriction compared with the control group of AGA babies (33). However, further work is necessary to substantiate this proposition.

In singleton IUGR babies alterations in fetal plasma concentration of nonessential amino acids are variable. In this study, we found a marked decrease in the fetal levels and F/M ratios of taurine, in the donor twin compared with the recipient twin. This is consistent with data reported for singleton IUGR pregnancies (14). A more recent study suggests that reduced plasma taurine concentrations in singleton IUGR fetuses is due to the reduced activity of placental taurine transporters (34). However, the physiologic function of this amino acid remains 
elusive. Normal fetal and neonatal development is critically dependent on the availability of taurine. Animal and human data also suggests that taurine deficiency may have detrimental effects on human development including visual impairment, and neurologic deficits $(35,36)$. Some investigators have therefore, considered taurine to be an essential amino acid in fetal life (37). We also found markedly elevated levels of taurine in polyhydramnic recipient twins. The function of increased levels of taurine in the recipient twin is also not clear. There is some evidence that taurine has an important role in cellular osmo-regulation, membrane stability, and in the defense against free radicals (38). We suggest that the increased flux of taurine may play a role in placental cell volume regulation of the hydropic recipient twins.

In the donor twin, the plasma serine and glycine concentrations were significantly reduced, compared with the recipient twin. This data are consistent with that obtained from singleton growth retarded fetuses. It is well established in normal pregnancy that the transport of serine and glycine from mother to fetus across the human and ovine placenta is minimal (39). Thus, the fetus relies on the endogenous production of serine and glycine. In the fetal circulation, predominant source of serine is its active synthesis from glycine within the liver. However, approximately $25 \%$ is also derived from the transamination reactions involving glutamine, glutamate and alanine (40). In contrast, glycine in the fetal circulation is derived by placental conversion of serine. The low levels of these two amino acids could, therefore, be attributed to the immaturity of the various enzymes that are essential for the biosynthesis pathways. Alternatively, impaired gluconeogenesis in the hypoxic and acidotic donor twin may further reduce the plasma levels of serine and glycine.

Higher levels of alanine in the donor twin may be a result of reduced oxygenation or gluconeogenesis. The hypoxemiarelated increase in plasma alanine levels in the fetus has been shown in animal and human studies. For example when fetal sheep are exposed to hypobaric hypoxia and human neonates are asphyxiated at birth, the plasma concentration of alanine is increased $(41,42)$. Fetal blood sampling studies have provided evidence of chronic hypoxia and acidosis in the donor twin of chronic TTTS pregnancies (12). Alternatively, increased alanine levels in the donor twin may be a result of decreased protein synthesis because of hepatic dysfunction. Total plasma protein concentration in the donor twin is known to be less than that of the recipient twin (43).

In conclusion, we report for the first time marked differences in five essential amino acid concentrations between $\mathrm{MC}$ twin pairs with discordant growth. No such differences were present between concordant $\mathrm{MC}$ twin pairs and the levels of amino acids seen were similar to those of the recipient twin. These selective differences in amino acid concentrations are likely to be a consequence of discordant placental transport. These data further strengthen the argument against the traditional theory of inter-twin transfusion being the principal cause of growth restriction in the donor twin. However, further studies are warranted to evaluate the placental syncytiotrophoblast amino acid transporter activities in respective parts of the MC twin placenta to elucidate the underlying mechanism and to clarify the role of placenta in the regulation of fetal growth in monochorionic twins.

Acknowledgments. The authors thank the staff of the delivery units at the Hammersmith Trust Hospitals, London, and St Mary's Hospital, Manchester, for assistance with collection of blood samples.

\section{REFERENCES}

1. Bajoria R, Kingdom JCP 1997 A case for routine determination of chorionicity in multiple pregnancies. Prenat Diagn 17:1207-1225

2. Benirschke K, Kaufmann P 1995 Multiple pregnancy. In: Pathology of the Human Placenta, 3rd Ed. Springer-Verlag, New York, pp 636-753

3. Zosmer N, Bajoria R, Weiner E, Rigby M, Vaughan J, Fisk NM 1994 Clinical and echographic features of in utero cardiac dysfunction in the recipient twin in twin-twin transfusion syndrome. Br Heart J 72:74-79

4. Hecher K, Plath H, Bregenzer T, Hansmann M, Hackeloer BJ 1999 Endoscopic laser surgery versus serial amniocenteses in the treatment of severe twin-twin transfusion syndrome. Am J Obstet Gynecol 180:717-724

5. Bajoria R 1998 Chorionic plate vascular anatomy determines the efficacy of amnioreduction therapy for twin-twin transfusion syndrome. Hum Reprod 13:1709-1713

6. Bajoria R; Wigglesworth J; Fisk N 1995 Angioarchitecture of monochorionic placentas in relation to the twin twin transfusion syndrome. Am J Obstet Gynecol $172: 856-863$

7. Machin G, Still K, Lalani T 1996 Correlations of placental vascular anatomy and clinical outcomes in 69 monochorionic twin pregnancies. Am J Med Genet 61:229236

8. Bajoria R 1998 Vascular anatomy of monochorionic placenta in relation to discordant growth and amniotic fluid volume. Hum Reprod 13:2933-2940

9. Bajoria R, Lazda EJ, Ward BS, Sooranna SR 2000 Iron metabolism in monochorionic twin pregnancies in relation to twin-twin transfusion syndrome. J Soc Gynecol Invest 7:259A

10. Bruner JP, Anderson TL, Rosemond RL 1998 Placental pathophysiology of the twin oligohydramnios-polyhydramnios sequence and the twin-twin transfusion syndrome. Placenta 19:81-86

11. Hecher K, Ville Y, Snijders R, Nicolaides K 1995 Doppler studies of the fetal circulation in twin-twin transfusion syndrome. Ultrasound Obstet Gynecol 5:318-324

12. Berry SM, Puder KS, Bottoms SF, Uckele JE, Romero R, Cotton DB 1995 Comparison of intrauterine hematologic and biochemical values between twin pairs with and without stuck twin syndrome. Am J Obstet Gynecol 172:1403-1410

13. Cetin I, Corbetta C, Sereni LP, Marconi AM, Bozzetti P, Pardi G, Battaglia FC 1990 Umbilical amino acid concentrations in normal and growth-retarded fetuses sampled in utero by cordocentesis. Am J Obstet Gynecol 162:253-261

14. Economides DL, Nicolaides KH, Gahl WA, Bernardini I, Evans MI 1989 Plasma amino acids in appropriate- and small-for-gestational-age fetuses. Am J Obstet Gynecol 161:1219-1227

15. McIntosh N, Rodeck CH, Heath R 1984 Plasma amino acids of the mid-trimester human fetus. Biol Neonate 45:218-224

16. Danskin FH, Neilson JP 1989 Twin-to-twin transfusion syndrome: what are appropriate diagnostic criteria? Am J Obstet Gynecol 161:365-369

17. Carroll SG, McLennan A, Maxwell DJ 1997 Fetal hemoglobin changes in the twin oligohydramnios-polyhydramnios sequence. Ultrasound Obstet Gynecol 9:398-402

18. Saunders NJ, Snijders RJ, Nicolaides KH 1991 Twin-twin transfusion syndrome during the 2nd trimester is associated with small intertwin hemoglobin differences. Fetal Diagn Ther 6:34-36

19. Robinson J, Chidzanja S, Kind K, Lok F, Owens P, Owens J 1995 Placental control of fetal growth. Reprod Fertil Dev 7:333-344

20. Cetin I, Marconi AM, Corbetta C, Lanfranchi A, Baggiani AM, Battaglia FC, Pardi G 1992 Fetal amino acids in normal pregnancies and in pregnancies complicated by intrauterine growth retardation. Early Hum Dev 29:183-186

21. Cetin I, Marconi AM, Bozzetti P, Sereni LP, Corbetta C, Pardi G, Battaglia FC 1988 Umbilical amino acid concentrations in appropriate and small for gestational age infants: a biochemical difference present in utero. Am J Obstet Gynecol 158:120-126

22. Bower SJ, Flack NJ, Sepulveda W, Talbert DG, Fisk NM 1995 Uterine artery blood flow response to correction of amniotic fluid volume. Am J Obstet Gynecol 173:502 507

23. Liechty EA, Boyle DW, Moorehead H, Lee WH, Bowsher RR, Denne SC 1996 Effects of circulating IGF-I on glucose and amino acid kinetics in the ovine fetus. Am J Physiol 271:E177-E185

24. Kniss DA, Shubert PJ, Zimmerman PD, Landon MB, Gabbe SG 1994 Insulin like growth factors. Their regulation of glucose and amino acid transport in placental trophoblasts isolated from first-trimester chorionic villi. J Reprod Med 39:249-256

25. Ozkan H, Aydin A, Demir N, Erci T, Buyukgebiz A 1999 Associations of IGF-I, IGFBP-1 and IGFBP-3 on intrauterine growth and early catch-up growth. Biol Neonate $76: 274-282$

26. Godfrey KM, Matthews N, Glazier J, Jackson A, Wilman C, Sibley CP 1998 Neutral amino acid uptake by the microvillous plasma membrane of the human placenta is inversely related to fetal size at birth in normal pregnancy. J Clin Endocrinol Metab $83: 3320-3326$

27. Jansson T, Scholtbach V, Powell TL 1998 Placental transport of leucine and lysine is reduced in intrauterine growth restriction. Pediatr Res 44:532-537 
28. Glazier JD, Cetin I, Perugino G, Ronzoni S, Grey AM, Mahendran D, Marconi AM, Pardi G, Sibley CP 1997 Association between the activity of the system A amino acid transporter in the microvillous plasma membrane of the human placenta and severity of fetal compromise in intrauterine growth restriction. Pediatr Res 42:514-519

29. Mahendran D, Donnai P, Glazier JD, D'Souza SW, Boyd RD, Sibley CP 1993 Amino acid (system A) transporter activity in microvillous membrane vesicles from the placentas of appropriate and small for gestational age babies. Pediatr Res 34:661-665

30. Marconi AM, Paolini CL, Stramare L, Cetin I, Fennessey PV, Pardi G, Battaglia FC 1999 Steady state maternal-fetal leucine enrichments in normal and intrauterine growth-restricted pregnancies. Pediatr Res 46:114-119

31. Cetin I, Ronzoni S, Marconi AM, Perugino G, Corbetta C, Battaglia FC, Pardi G 1996 Maternal concentrations and fetal-maternal concentration differences of plasma amino acids in normal and intrauterine growth-restricted pregnancies. Am J Obstet Gynecol 174:1575-1583

32. Ayak PTY, Theophanous D, Glazier JD, D'Souza S, Sibley CP 1999 L-arginine transport across the microvillous plasma membrane of the human placental syncytiotrophoblast from normal, pre-eclamptic and IUGR pregnancies. J Soc Gynecol Invest $6: 85 \mathrm{~A}$

33. Lyall F, Greer IA, Young A, Myatt L 1996 Nitric oxide concentrations are increased in the feto-placental circulation in intrauterine growth restriction. Placenta 17:165168
34. Norberg S, Powell TL, Jansson T 1998 Intrauterine growth restriction is associated with a reduced activity of placental taurine transporters. Pediatr Res 44:233-238

35. Sturman JA 1988 Taurine in development. J Nutr 118:1169-1176

36. Ghisolfi J 1987 Taurine and the premature. Biol Neonate 52(suppl 1):78-86

37. Sturman JA.1993 Taurine in development. Physiol Rev 73:119-147

38. Shennan DB, McNeillie SA, Curran DE 1993 Stimulation of taurine efflux from human placental tissue by a hypoosmotic challenge. Exp Physiol 78:843-846

39. Geddie G, Moores R, Meschia G, Fennessey P, Wilkening R, Battaglia FC 1996 Comparison of leucine, serine and glycine transport across the ovine placenta. Placenta 17:619-627

40. Moores RR Jr, Rietberg CC, Battaglia FC, Fennessey PV, Meschia G 1993 Metabolism and transport of maternal serine by the ovine placenta: glycine production and absence of serine transport into the fetus. Pediatr Res 33:590-594

41. Guyton TS, De Wilt H, Fennessey PV, Meschia G, Wilkening RB, Battaglia FC 1993 Alanine umbilical uptake, disposal rate, and decarboxylation rate in the fetal lamb. Am J Physiol 265:E497-E503

42. Gilfillan CA, Tserng KY, Kalhan SC 1985 Alanine production by the human fetus at term gestation. Biol Neonate 47:141-147

43. Bryan EM, Slavin B, Nicholson E 1976 Serum immunoglobulins in multiple pregnancy. Arch Dis Child 51:354-359 